\title{
Analysis of Different Pressure Thermally Coupled Extractive Distillation Column
}

\author{
Lanyi Sun*, Kang He, Yuliang Liu, Qiuyuan Wang and Dingding Wang
}

State Key Laboratory of Heavy Oil Processing, China University of Petroleum, Qingdao266580, Shandong, China

\begin{abstract}
In this contribution, a different pressure thermally coupled extractive distillation process has been applied on the separation of propylene and propane with aqueous acetonitrile (ACN) solution as entrainer. The novel distillation process integration is the combination of different pressure thermally coupled distillation (DPTCD) and extractive distillation (ED). Both the new process and the conventional process have been simulated in Aspen Plus. Sensitivity analysis has been conducted to select an appropriate compression ratio and other operating parameters based on the priority that the propylene product purity is $99.2 \mathrm{wt} \%$ and less energy consumption. The influence of the proposed distillation column on energetic and economic aspects is evaluated through intensive comparison against the conventional stand-alone column, and better performance is achieved with up to $46.02 \%$ energy saving and close to $9.7 \%$ saving in total annual cost (TAC).
\end{abstract}

Keywords: Different pressure thermally coupled, Extractive distillation, Propylene, Propane, Energy saving, TAC.

\section{INTRODUCTION}

Distillation is a unit operation most widely used in petrochemical processes [1], which is also known for its high energy requirement and poor thermodynamic efficiency. Propylene is mostly used to produce polypropylene, acrylonitrile, propylene oxide and acetone. With the increasing of demand for propylene derivatives, the production of propylene has become more and more important. Since most propylene comes from pyrolysis gases, the separation of propylene in ethylene projects behaves great commercial significance. In ethylene projects, propylene is purified from a mixture mainly composed of propylene and propane [2].

Because the boiling points of propane and propylene are very close over a large range of pressure, it always needs a huge investment in equipment and much energy requirement to separate them by conventional distillation. Extractive distillation (ED), an important separation method in chemical engineering [3,4], is used to separate compounds with similar boiling points by using an additional entrainer to alter the relative volatility [5]. Liao et al. [2] had used extractive distillation for the propane-propylene separation and achieved excellent purity of propylene. The ED makes separation easy, but it still needs considerable energy requirement because of the addition of entrainer.

Distillation requires a large proportion of the energy used in the chemical process industries. Consequently, there is a significant incentive to improve the energy efficiency [6] of this widely applied separation process [7]. Li et al. [8] proposed the general structure of different pressure thermally

*Address correspondence to this author at the State Key Laboratory of Heavy Oil Processing, China University of Petroleum, Qingdao266580, Shandong, China; Tel.: +86-138-5420-8340; Fax.: +86-0532-8698-1787;

E-Mail: sunlanyi@upc.edu.cn coupled distillation (DPTCD) column. For a typical DPTCD column, the conventional distillation column is divided into two columns with different pressures, a high-pressure (HP) column and a low-pressure (LP) column. The overhead vapor of the HP column is used as the heat source of the reboiler of the LP column, therefore the thermally coupled process is realized and this intensified energy integration approach reduces the steam consumption in the reboiler and avoids the use of a condenser. The DPTCD technology is used in the separation of propane-propylene and C4's hydrocarbon, and comparing with conventional distillation, the energy requirement could be reduced by $92.3 \%$ and $87.1 \%$, respectively.

In this paper, a novel distillation process integration method by combining DPTCD with ED principles is addressed. The resulting integrated unit is referred to as the different pressure thermally coupled extractive distillation (DPTCED), which contains the advantages of both ED and DPTCD. By simulating the ED and DPTCED columns with Aspen Plus simulator, a series of analyses on energy saving and total annual cost (TAC) have been presented.

\section{PROCESS DESCRIPTION}

\subsection{Selection of the Vapor-Liquid Equilibrium Model}

For chemical process simulation, property methods have a significant influence on the simulation results. Liao et al. [2] set up an air-lift apparatus to measure the relative volatility at infinite dilution by inert gas stripping and gas chromatography methods $[9,10]$, by which a series of relative volatilities at infinite dilution of aqueous acetonitrile (ACN)propane-propylene system was measured and the results are given in Table 1. The UNIFAC group contribution [11-14] method is the most commonly used model in the calculation of extractive distillation. The calculated values in terms of 
UNIFAC are in good agreement with experimental data as shown in Table $\mathbf{1}$.

\subsection{Conventional Extractive Distillation Process}

In this paper, $\mathrm{ACN}$ is used as the entrainer in the two processes. Fig. (1) gives a schematic diagram that illustrates the conventional extractive distillation (CED) process to separate the propylene and propane, which includes an ED column with 60 stages (including condenser and reboiler, similarly hereinafter) and a recovery column with 35 stages. The numbering of the stages is taken from the top of the column. The feed mixture enters at stage 31 of the ED column. The entrainer mixture containing $80 \mathrm{wt} \% \mathrm{ACN}$ and $20 \mathrm{wt} \%$ $\mathrm{H}_{2} \mathrm{O}$ enters the stage 6 of the ED column with the recycle stream from the recovery column. The product propane is obtained at the top of ED column. The mixture, which outflows from the bottom of ED column, is fed into the recovery column at stage 20 to separate propylene and ACN entrainer. The product purity of propylene is $99.2 \mathrm{wt} \%$. The bottom liquid of the recovery column is recycled to the ED column with fresh entrainer. Table 2 shows the feed conditions of ED column.

\subsection{Different Pressure Thermally Coupled Extractive Distillation (DPTCED) Process}

The different pressure thermally coupled concept has been applied to the ED column keeping the input specifica- tions identical, and the DPTCED process is shown in Fig. (2). The ED column is divided into two columns, a HP column with the top pressure $1.8 \mathrm{MPa}$ and a LP column with the top pressure $0.55 \mathrm{MPa}$. The HP column consists of rectifying section and extractive distillation section, and the LP column consists of extractive distillation section and stripping section. The liquid outflow from the bottom of HP column is driven to the top of LP column. The overhead vapor of LP column is compressed by the compressor. The compression efficiency is 0.72 and the temperature rises in the compressor to keep the vapor from condensing. Then the compressed vapor is driven into the bottom of HP column. The bottom outflow from the LP column is fed into the recovery column. The detailed operating parameters for the CED and DPTCED processes are summarized in Table 3 . If the required condenser duty of HP column $\left(Q_{\text {cond }}\right)$ is larger than the reboiler duty of LP column $\left(Q_{\mathrm{reb}}\right)$, an auxiliary condenser should be added.

\section{SENSITIVITY ANALYSIS}

In the present study, many sensitivity analyses have been carried out to tune the operating variables. Here, the operating variables considered are the compression ratio $(C R)$ and the reflux ratio $(R R)$. Keeping the total number of stages fixed and the input conditions the same for both distillation columns, the variables of DPTCED column are systematically tuned to obtain the conditions that meet the product specification and require less energy.

Table 1. Comparison of the experimental data and calculated values.

\begin{tabular}{|c|c|c|c|}
\hline \multirow{2}{*}{ Solvent } & \multirow{2}{*}{ Temperature $\left({ }^{\circ} \mathbf{C}\right)$} & \multicolumn{2}{|c|}{ Infinite Dilution Relative Volatility } \\
\cline { 3 - 4 } & & Experimental Data & Calculated Values of UNIFAC \\
\hline \hline $\mathrm{ACN}$ & 18.9 & 1.69 & 1.71 \\
\hline $\mathrm{ACN}$ & 30 & 1.62 & 1.70 \\
\hline $\mathrm{ACN}+10 \mathrm{wt} \% \mathrm{H}_{2} \mathrm{O}$ & 15.5 & 1.75 & 1.85 \\
\hline
\end{tabular}

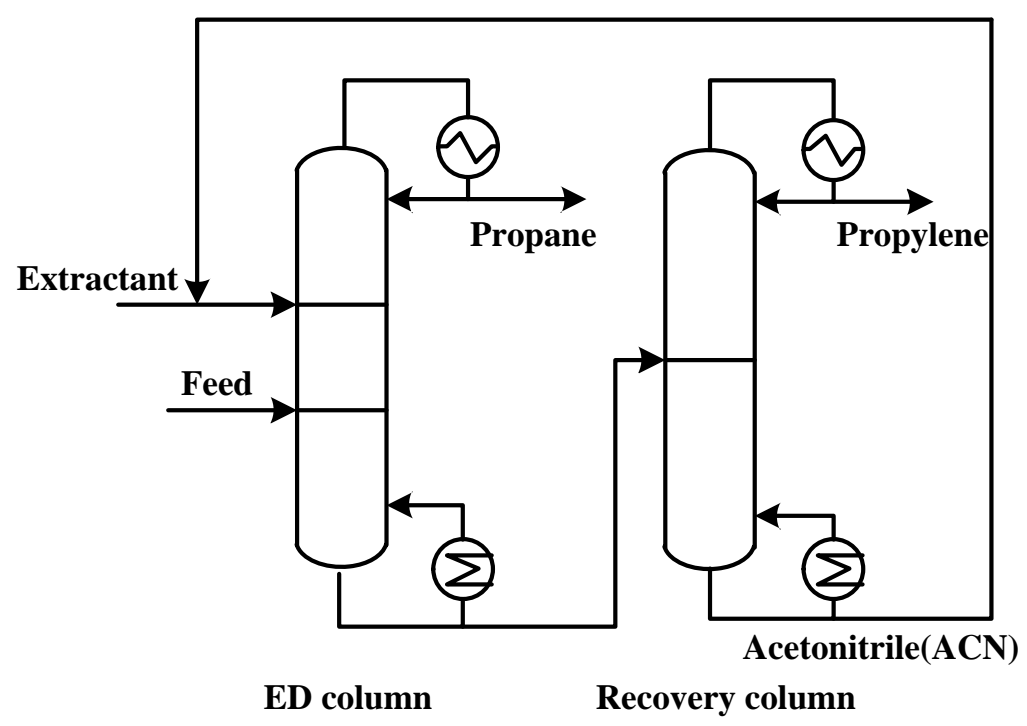

Fig. (1). Schematic diagram of a conventional extractive distillation (CED) process. 
Table 2. The feed conditions of ED column.

\begin{tabular}{|c|c|c|}
\hline Streams & Feed & Extractant \\
\hline \hline Temperature & $25^{\circ} \mathrm{C}$ & $2{ }^{\circ} \mathrm{C}$ \\
\hline Pressure & $1.81 \mathrm{MPa}$ & 0 \\
\hline Vapor fraction & 0 & $7500 \mathrm{~kg} / \mathrm{hr}$ \\
\hline Feed flow rate & $1500 \mathrm{~kg} / \mathrm{hr}$ & 0 \\
\hline & Feed composition (Mass fraction) & 0 \\
\hline Methane & 0.0005 & 0 \\
\hline Ethane & 0.002 & 0 \\
\hline Ethylene & 0.002 & 0 \\
\hline Propane & 0.25 & 0.8 \\
\hline Propylene & 0.746 & 0.2 \\
\hline ACN & 0 & 0 \\
\hline Water & 0 & 0 \\
\hline
\end{tabular}

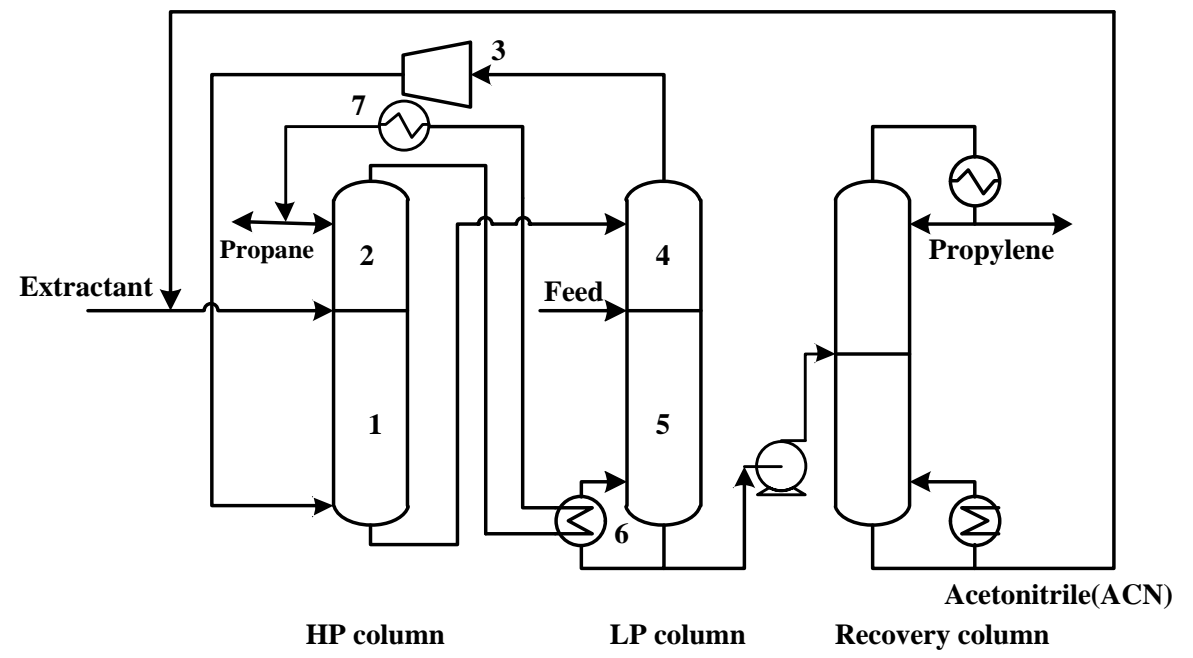

Fig. (2). Schematic diagram of a different pressure thermally coupled extractive distillation (DPTCED) process

The overall energy requirement $\left(Q_{\text {cons }}\right)$ of the DPTCED column is determined by adding the reboiler duty of the LP column $\left(Q_{\text {reb }}\right)$ to three times the compressor duty ( $\left.Q_{\text {comp }}\right)$.

The factor 3 for the compression duty is supposed to convert the compression work into the thermal energy required to produce an equivalent amount of electrical power [15].

\subsection{Selection of Compression Ratio}

Fig. (3) and (4) illustrate how the compression ratio $(C R)$ affects the heat transfer temperature difference $(\Delta T)$ and the energy requirement, respectively. Here, $\Delta T$ refers to the difference between the top temperature of HP column and the bottom temperature of LP column. Fig. (3) shows $\Delta T$ gradually increases as the $C R$ increases. Fig. (4) shows that with $C R$ increasing, there is no significant difference in the condenser duty of HP column $\left(Q_{\text {cond }}\right)$ while $Q_{\text {reb }}$ decreases.

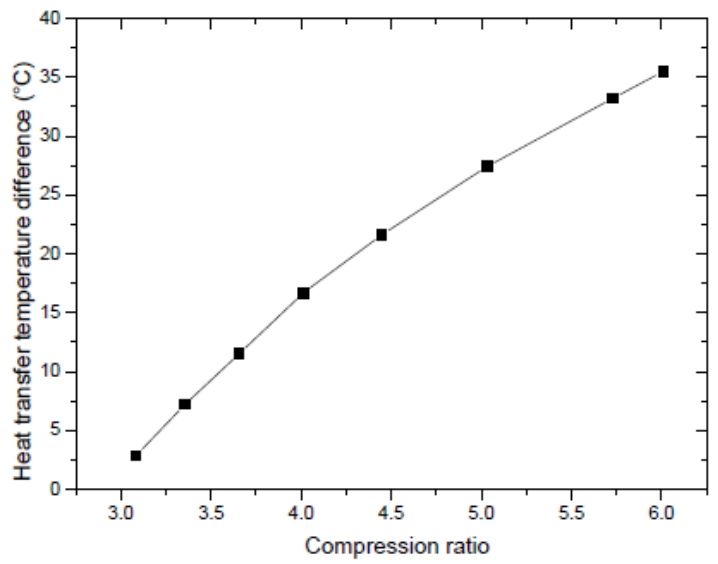

Fig. (3). The effect of compression ratio on the heat transfer temperature difference. 
However, $Q_{\text {comp }}$ and $Q_{\text {cons }}$ increase at the same time. To meet $\Delta T$ requirement and reduce energy requirement, the $C R$ of 3.64 has been selected.

\subsection{Selection of Reflux Ratio}

This simulation investigates the behavior of DPTCED column in terms of $\Delta T$ and the energy requirement with respect to the reflux ratio $(R R)$. The results are obtained in Fig. (5) and (6) with the fixed value of $C R$.

On the one hand, Fig. (5) shows that the maximum $\Delta T$ appears when the $R R$ is 8 , but $\Delta T$ changes little with the further increasing of $R R$. On the other hand, it is displayed in Fig. (6) that the energy requirement constantly increases with the increasing $R R$ mainly due to the increasing of $Q_{\text {reb. }}$ In order to achieve better separation efficiency and stable operation, the $R R$ of 10 is selected.

\subsection{Stage Pressure Drop}

The influence of stage pressure drop $(\Delta P)$ on $\Delta T$ and energy consumption is displayed in Fig. (7) and (8), respectively.

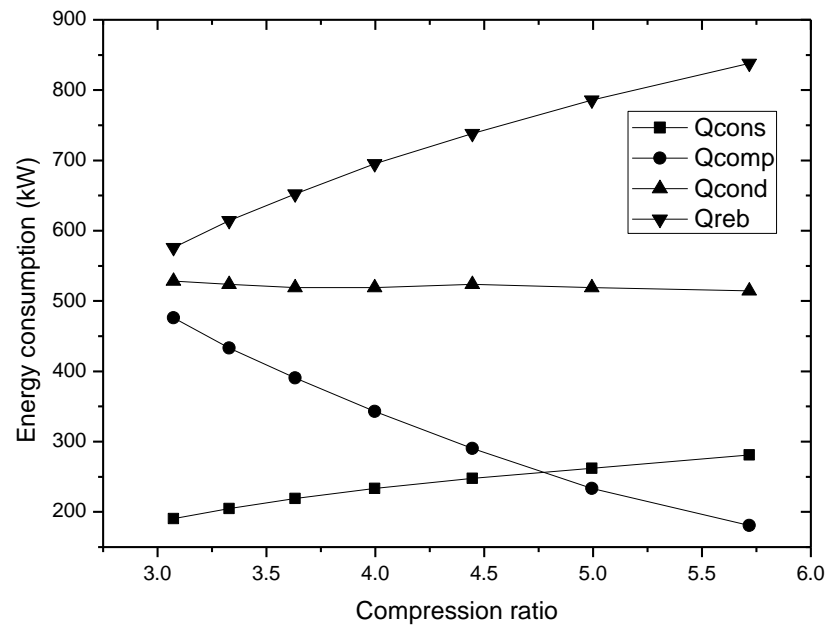

Fig. (4). The effect of compression ratio on the energy consumption.

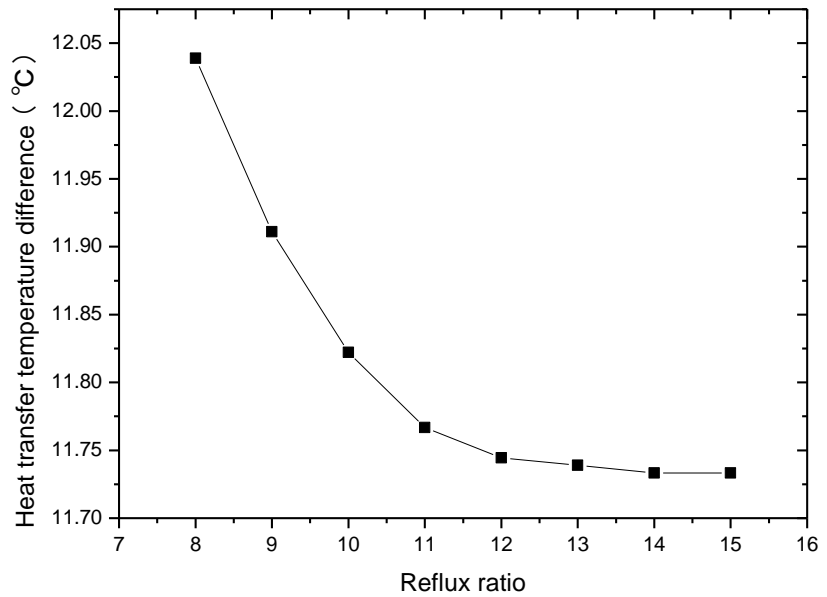

Fig. (5). The effect of reflux ratio on the heat transfer temperature difference.
This simulation experiment is performed considering $C R$ of 3.64 along with fixed total number of stages and $R R$ of 10 . $\Delta T$ starts falling slowly with the increasing of $\Delta P$, which results from the decrease in the flow rates inside the column. The energy consumption has no significant change with the increasing of $\Delta P$.

The subsequent discussion is based on the DPTCED column having $C R$ of $3.64, R R$ of $10, \Delta P$ of $0.3 \mathrm{kPa}$.

\section{ENERGY SAVING}

A comparison in terms of energy saving is conducted in Table 4. The overall energy consumption of DPTCED $\left(Q_{\mathrm{DPTCED}}\right)$, and CED $\left(Q_{\mathrm{CED}}\right)$, are obtained as $580.92 \mathrm{~kW}$ and $1076.2 \mathrm{~kW}$, respectively. The energy saving can be defined as

energy saving $=\frac{Q_{\mathrm{CED}}-Q_{\mathrm{DPTCED}}}{Q_{\mathrm{CED}}} \times 100$

We can figure out that the energy saving of $46.02 \%$ is achieved by DPTCED, which proves the successful application of the different pressure thermally coupled concept.

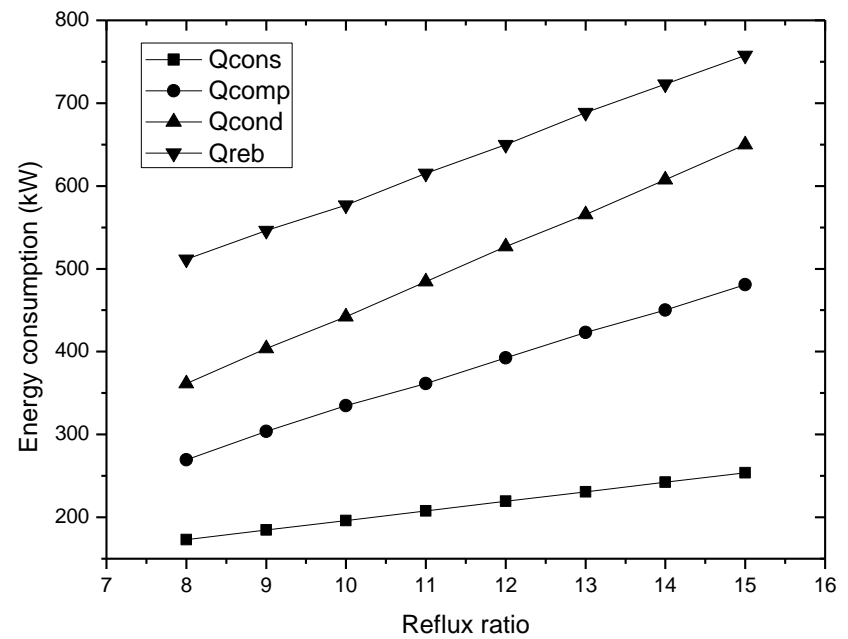

Fig. (6). The effect of reflux ratio on the energy consumption.

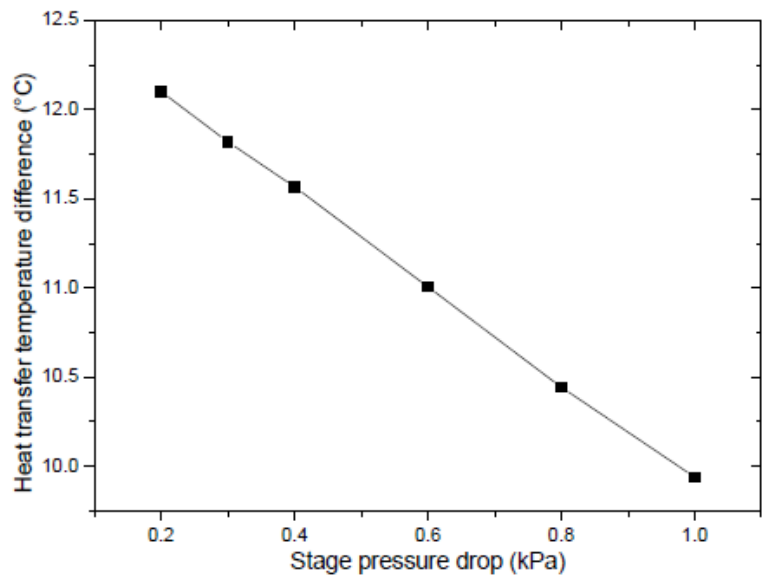

Fig. (7). The effect of stage pressure drop on the heat transfer temperature difference. 


\section{ECONOMIC EVALUATION}

The energy integration in a distillation process may provide a significant energy saving, but at the cost of an increased capital investment. This work presents an economic comparison, in terms of the TAC between CED and DPTCED.

$\mathrm{TAC}(\$ / \mathrm{yr})=O C+\frac{C I}{\theta}$

In this formula, $O C$ is the operating cost, $C I$ the capital investment, and $\theta$ the payback period. $C I$ includes the cost of equipment (distillation column (s), heat exchangers, and compressor (s)) and $O C$ includes the cost of utilities (heating steam, cooling water, and electricity) for a year which contains 8000 operating hours. The annual capital investment is calculated by assuming a payback period of 5 years. The capital cost and operation cost of CED and DPTCED are

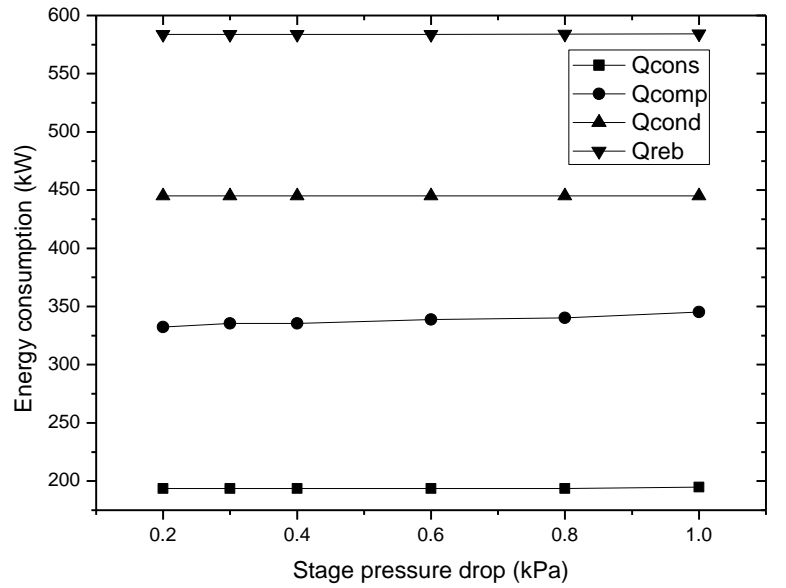

Fig. (8). The effect of stage pressure drop on the energy consumption.

Table 3. Operating Parameters for the CED and DPTCED Processes.

\begin{tabular}{|c|c|c|c|c|c|}
\hline Item & \multicolumn{2}{|c|}{ CED } & \multicolumn{3}{|c|}{ DPTCED } \\
\hline Feed tray & $6 / 31$ (entrainer/feed) & 20 & 6 & 1 & 20 \\
\hline Operating pressure & $1.8 \mathrm{MPa}$ & $1.2 \mathrm{MPa}$ & $1.8 \mathrm{MPa}$ & $0.55 \mathrm{MPa}$ & $1.2 \mathrm{MPa}$ \\
\hline Top product & $380 \mathrm{~kg} / \mathrm{hr}$ & $1010 \mathrm{~kg} / \mathrm{hr}$ & $490 \mathrm{~kg} / \mathrm{hr}$ & $8510 \mathrm{~kg} / \mathrm{hr}$ & $1010 \mathrm{~kg} / \mathrm{hr}$ \\
\hline \multicolumn{6}{|c|}{ Product composition (Mass fraction) } \\
\hline Methane & 0.002 & 0 & 0.0015 & l & 0 \\
\hline Propylene & $146 \mathrm{ppm}$ & 0.992 & 0.2182 & l & 0.9987 \\
\hline $\mathrm{ACN}$ & 0.0015 & 0 & 0.0017 & I & 0 \\
\hline Water & 0.017 & 0 & 0.0052 & l & 0 \\
\hline
\end{tabular}

Table 4. Comparison of Energy Consumption for CED and DPTCED.

\begin{tabular}{|c|c|c|c|}
\hline \multirow{2}{*}{ Item } & \multirow{2}{*}{$\frac{\text { CED }}{\text { ED Column }}$} & \multicolumn{2}{|c|}{ DPTCED } \\
\hline & & HP Column & LP Column \\
\hline Condenser duty & $370.01 \mathrm{~kW}$ & l & / \\
\hline Reboiler duty & $1076.2 \mathrm{~kW}$ & l & I \\
\hline Auxiliary condenser duty & l & \multicolumn{2}{|c|}{$109.28 \mathrm{~kW}$} \\
\hline Compressor duty & l & \multicolumn{2}{|c|}{$193.64 \mathrm{~kW}$} \\
\hline Total duty & $1076.2 \mathrm{~kW}$ & \multicolumn{2}{|c|}{$580.92 \mathrm{~kW}$} \\
\hline Energy saving & l & \multicolumn{2}{|c|}{$46.02 \%$} \\
\hline
\end{tabular}


estimated using the correlations given by Douglas [16]. Table 5 reports the cost of utilities [17].

It can be seen from Table $\mathbf{6}$ that savings of close to $9.7 \%$ in the TAC is achieved by DPTCED.

\section{CONCLUSIONS}

In this paper, a process of different pressure thermally coupled extractive distillation (DPTCED) is developed by dividing the conventional extractive distillation (CED) column into a high-pressure (HP) column and a low-pressure (LP) column. Along with the tuning of compression ratio and reflux ratio, a systematic parametric analysis is presented to investigate the effect of important parameters on the heat transfer temperature difference $(\Delta T)$ and energy requirement. However, the configuration developed cannot be considered as an optimal design but can be used as a good initialization point for an MINLP optimization procedure. Finally, an economic comparison between the DPTCED column and the CED column is reported. The potential energy integration leads to $46.02 \%$ energy saving and close to $9.7 \%$ saving in total annual cost.

\section{CONFLICT OF INTEREST}

The authors confirm that this article content has no conflict of interest.

\section{ACKNOWLEDGEMENTS}

This work was supported by the National Natural Science Foundation of China (21276279).

\section{ABBREVIATIONS}

$\begin{array}{lll}\mathrm{ACN} & = & \text { Acetonitrile } \\ \mathrm{TAC} & = & \text { Total Annual Cost } \\ \mathrm{ED} & = & \text { Extractive Distillation } \\ \text { DPTCD } & = & \text { Different Pressure Thermally Coupled } \\ \text { Distillation } & \text { High-Pressure } \\ \text { LP } & =\text { Low-Pressure } \\ \text { DPTCED } & =\text { Different Pressure Thermally Coupled }\end{array}$

Table 5. The Cost of Utilities.

\begin{tabular}{|c|c|}
\hline Item & Value \\
\hline \hline Steam & $17 \$ \bullet \operatorname{ton}^{-1}$ \\
\hline Cooling water & $0.06 \$ \bullet \mathrm{ton}^{-1}$ \\
\hline Electricity & $0.084 \$ \bullet \mathrm{kWh}^{-1}$ \\
\hline
\end{tabular}

Table 6. Comparison of Estimated Capital and Operating Costs.

\begin{tabular}{|c|c|c|c|}
\hline \multirow{2}{*}{ Item } & \multirow{2}{*}{$\frac{\text { CED }}{\text { ED Column }}$} & \multicolumn{2}{|c|}{ DPTCED } \\
\hline & & HP Column & LP Column \\
\hline \multicolumn{4}{|c|}{ Capital investment } \\
\hline Column shell cost & $203.24 \$ 1,000$ & $122.65 \$ 1,000$ & $82.42 \$ 1,000$ \\
\hline Trays cost & $10.48 \$ 1,000$ & $4.45 \$ 1,000$ & $2.64 \$ 1,000$ \\
\hline Heat exchanger cost & l & \multicolumn{2}{|c|}{$36.94 \$ 1,000$} \\
\hline Reboiler cost & $39.72 \$ 1,000$ & \multicolumn{2}{|c|}{ l } \\
\hline Condenser cost & $104.13 \$ 1,000$ & \multicolumn{2}{|c|}{$21.23 \$ 1,000$} \\
\hline Compressor cost & l & \multicolumn{2}{|c|}{$612.26 \$ 1,000$} \\
\hline TOTAL COST & $298.03 \$ 1,000$ & \multicolumn{2}{|c|}{$875.49 \$ 1,000$} \\
\hline \multicolumn{4}{|c|}{ Utilities } \\
\hline Stream cost & $277.18 \$ 1,000 \bullet$ year $^{-1}$ & l & l \\
\hline Cooling water cost & $16.67 \$ 1,000 \bullet$ year $^{-1}$ & \multicolumn{2}{|c|}{$4.99 \$ 1,000 \bullet$ year $^{-1}$} \\
\hline Electricity cost & l & \multicolumn{2}{|c|}{$130.13 \$ 1,000 \bullet$ year $^{-1}$} \\
\hline TOTAL COST & $293.85 \$ 1,000 \bullet$ year $^{-1}$ & \multicolumn{2}{|c|}{$135.11 \$ 1,000 \bullet$ year $^{-1}$} \\
\hline $\operatorname{TAC}(\theta=5$ years $)$ & $343.52 \$ 1,000 \bullet$ year $^{-1}$ & \multicolumn{2}{|c|}{$310.21 \$ 1,000 \bullet$ year $^{-1}$} \\
\hline
\end{tabular}




$\begin{array}{lll} & & \text { Extractive Distillation } \\ \mathrm{CED} & = & \text { Conventional Extractive Distillation } \\ C R & = & \text { Compression Ratio } \\ R R & = & \text { Reflux Ratio } \\ O C & = & \text { Operating Cost } \\ C I & = & \text { Capital Investment }\end{array}$

\section{REFERENCES}

[1] A. Tamir, "Chemical Engineering via Art", Open Chem. Eng. J., vol. 2, pp. 51-56, 2008.

[2] B. Liao, Z. Lei, Z. Xu, R. Zhou, and Z. Duan, "New process for separating propylene and propane by extractive distillation with aqueous acetonitrile", Chem. Eng. J., vol. 84, pp. 581-586, 2001.

[3] J. Martinez, P.T. Rosa, M. Meireles, A. Angela, "Extraction of clove and vetiver oils with supercritical carbon dioxide: modeling and simulation", Open Chem. Eng. J., vol. 1, pp. 1-7, 2007.

[4] M.M. Jaradata, M.M. Attarakiha, T. Steinmetzd, H.J. Bart, "LLECMOD: A bivariate population balance simulation tool for pulsed liquid-liquid extraction columns". Open Chem. Eng. J., vol. 6, pp. 8-31, 2012.

[5] R. Gutiérrez-Guerra, J.G. Segovia-Hernández, S. Hernández, "Reducing energy consumption and $\mathrm{CO}_{2}$ emissions in extractive distillation”. Chem. Eng. Res. Des., vol. 87, pp. 145-152, 2009.

[6] J.M. Honig, R. Hoehn, "Entropy of irreversible processes across a boundary". Open Chem. Eng. J., vol. 5, pp. 1-6, 2011.

[7] G. Liu, Z. Chen, K. Huang, Z. Shi, H. Chen, S. Wang, "Studies of the externally heat-integrated double distillation columns (EHIDDiC)". Asia-Pacific. J. Chem. Eng., vol. 6, pp. 327-337, 2011.
[8] H. Li, X. Li, M. Luo, "Different pressure thermally coupled distillation technology for energy saving". Chem. Indust. Eng. Prog., vol. 7, p. 035, 2008.

[9] P. Duhem, J. Vidal, "Extension of the dilutor method to measurement of high activity coefficients at infinite dilution", Fluid. Phase. Equilib., vol. 2, pp. 231-235, 1978.

[10] J.C. Lerol, J.C. Masson, H. Renon, J.F. Fabries, H. Sannier, “Accurate measurement of activity coefficient at infinite dilution by inert gas stripping and gas chromatography", Indust. Eng. Chem. Proc. Des. Develop., vol. 16, pp. 139-144, 1977.

[11] A. Fredenslund, R.L. Jones, J.M. Prausnitz, "Group-contribution estimation of activity coefficients in nonideal liquid mixtures". AIChE. J., vol. 21, pp. 1086-1099, 1975.

[12] S. Skjold-Jorgensen, B. Kolbe, J. Gmehling, P. Rasmussen, "Vapor-liquid equilibria by UNIFAC group contribution. Revision and extension”. Indust. Eng. Chem. Proc. Des. Develop., vol. 18, pp. 714-722, 1979.

[13] E.A. Macedo, U. Weidlich, J. Gmehling, P. Rasmussen, "Vaporliquid equilibriums by UNIFAC group contribution. Revision and extension". Indus. Eng. Chem. Proc. Desig. Develop., vol. 22, pp. 676-678, 1983.

[14] H.K. Hansen, P. Rasmussen, A. Fredenslund, M. Schiller, J. Gmehling, "Vapor-liquid equilibria by UNIFAC group contribution. 5. Revision and extension". Indust. Eng. Chem. Res., vol. 30, pp. 2352-2355, 1991.

[15] K. Iwakabe, M. Nakaiwa, K. Huang, T. Nakanishi, A. Røsjorde, T. Ohmori, T. Yamamoto, "Energy saving in multicomponent separation using an internally heat-integrated distillation column (HIDiC)", App. Therm. Eng., vol. 26, pp. 1362-1368, 2006.

[16] J.M. Douglas, Conceptual Design of Chemical Processes, 1st ed.; New York: McGraw-Hill Companies Inc., 1988.

[17] A. Mane, A.K. Jana, "A new intensified heat integration in distillation column", Indust. Eng. Chem. Res., vol. 49, pp. 9534-9541, 2010. 